J. Zool., Lond. (1977) 182, 477-494

\title{
Locomotory and other movements of the trunk of Bonellia viridis (Echiura, Bonelliidae)
}

\author{
P. J. SChembri and V. Jaccarini \\ The Fort San Lucian Marine Station, The University of Malta
}

(Accepted 9 November 1976)

(With 1 plate and 7 figures in the text)

\begin{abstract}
Trunk irrigatory and locomotory movements in the echiuran Bonellia viridis consist of peristaltic waves of constriction. Irrigation is by antero-posterior waves. Locomotion in the burrow may be produced in three different ways: (a) by antikinetic, (b) by synkinetic, and (c) by antikinetic and synkinetic waves in strict alternation. The animal can turn in the burrow and pass out of narrow holes. The animal can move by peristaltic waves also outside its burrow. The versatility of locomotory modes is related to its inhabiting ready-made burrows.
\end{abstract}

\section{Contents}

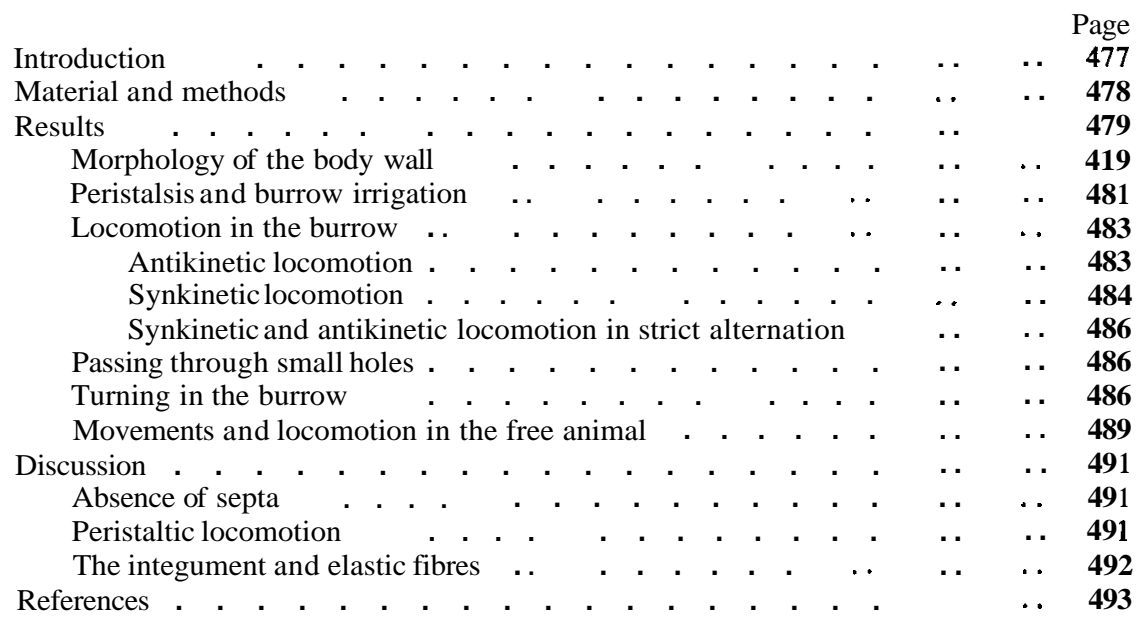

\section{Introduction}

Locomotory and other movements in annelids have been the subject of extensive observation and theoretical analysis since the classical work of Gray \& Lissman (1938) and Gray (1939) on locomotion in the earthworm and Nereis respectively. Suffice it to mention the work of Wells $(1944 ; 1949 a, \boldsymbol{b} ; 1954)$, Trueman $(1966 a, b)$, and Seymour $(1970 ; 1971)$ on Arenicola; that of Clark \& Clark (1960) on Nephytys; Mettam (1969) on Sabella; and Elder (1973a) on Polyphysia. Clark (1964), Gray (1968) and Trueman (1974) provide reviews and theoretical discussions.

Locomotion in vermiform animals is often by means of peristaltic waves which travel along the animal either in the same direction as the animal is moving (direct or synkinetic 
waves) or else in the opposite direction (retrograde or antikinetic waves). Whether locomotion is synkinetic or antikinetic depends on whether that part of the body wall forming the point d'appui or "foot" is fully extended or fully shortened (Gray, 1968).

The echiurans too have attracted some attention. Gislén (1940) gave an account of the creeping, digging, burrow irrigation and swimming activities of Echiurus echiurus. E. echiurus creeps forwards on a soft substrate by means of antikinetic peristaltic waves in the manner of the earthworm and uses its oral setae, and sometimes its ventral setae as anchors. The animal digs into a soft substrate by alternately scraping with the ventral setae and rooting with the blown-up front end. It is not clear from Gislen's account what role, if any, peristaltic waves play in the digging process, though he remarks that "rarely I have seen forward running peristaltic waves which then may cooperate at digging". In contrast, burrow irrigation is by means of antero-posterior peristalsis. Gislén also analyses the swimming of Echiurus, which takes place by means of spiral coiling and uncoiling of the trunk. This had been observed previously by Forbes \& Goodsir (1841) and by Wilson (1900).

In Ochetostoma erythrogrammon antero-posterior peristaltic waves passing along the trunk pump water through the burrow for respiratory purposes, (Chuang, 1962).

Fisher \& MacGinitie (1928) studied both the locomotory and the respiratory movements of Urechis caupo. They describe Urechis as moving "along a smooth surface in much the same manner as an earthworm". It seems clear from their further description that the animal moves by means of antikinetic peristaltic waves. Its method of locomotion in a burrow is quite similar except that the animal now wedges "the anterior portion against the sides of the burrow". It can move both backwards and forwards at nearly equal speeds. Irrigation of the burrow is by means of antero-posterior peristalsis of the trunk and also by inhalations and exhalations of water through the anus into and out of the hindgut. Lawry (1966a) described the anatomy of the neuromuscular system of Urechis and analysed the muscular activity underlying peristalsis. He found that Urechis has two pacemakers, an anterior and a posterior one, which initiate antero-posterior peristalsis and anal respiratory movements, respectively. Lawry (1966b) located the anterior and posterior pacemakers and provided evidence for a hierarchy of pacemaker regions in the nerve cord. This hierarchy is normally dominated by the anterior pacemaker.

The accounts of movement in Bonellia viridis Rolando, 1822 in the literature are of a very general nature. Lacaze-Duthiers (1858) notes that $\boldsymbol{B}$. viridis enters holes in the substrate backwards by means of frequent peristaltic movements but does not make clear whether these are synkinetic or antikinetic. Rietsch (1886) describes $B$. minor as entering holes both backwards by means of the trunk and also by introducing its proboscis and then pulling its trunk towards the terminal lobes.

The purpose of the present work is to give a detailed account of respiratory and locomotory movements of the trunk in Bonellia and to analyse the mechanism of such movements. These are produced by peristalsis of the body wall. Movements of the proboscis which are mainly ciliary are described in Jaccarini \& Schembri (1977).

\section{Material and methods}

Bonellia viridis were collected from the bay directly below the Fort San Lucian Marine Station of the University of Malta at Marsaxlokk. The animals were found mostly in burrows in soft calcareous rock and sometimes lying free under stones in about 10 feet of water. The rocks 
containing Bonellia were kept in marine aquaria. The worms were obtained as required by carefully cleaving the rocks to expose the worms. Fully grown animals occupy burrows of 10-20 mm diameter. Unless otherwise stated all observations were made on animals placed in glass tubes of $13-14.5 \mathrm{~mm}$ internal diameter and open at both ends. The tubes were placed in perspex tanks with continuously circulating well aerated seawater. Observations were also made on the animals in their natural burrows both in marine aquaria in the laboratory and also in the sea.

Detailed analysis of the movements of the animals was made cinematographicallyusing a Bolex H16 SBM camera and a Bolex 421 projector. The animals both free and inside glass tubes were placed on a $2 \mathrm{~mm}$-square grid in a shallow container and photographed at $18 \mathrm{frames} / \mathrm{sec}$. Frame by frame analysis was made. The diagrams are based on tracings of projected images.

The water currents set up by the worms were followed by adding particles of calcium sulphate to the water. The rate at which water was pumped through tubes in the process of irrigation was measured using the method of Hall (1931).

For histology animals were fixed in seawater Bouin's and embedded in paraffin wax. Transverse and vertical longitudinal sections were cut at $8 \mu \mathrm{m}$ and stained with haematoxylin and eosin, or Masson's trichrome stain. The distribution of elastic fibres in the body wall was studied in sections stained by the potassium permanganate/spirit blue method of Elder \& Owen (1967).

\section{Results \\ Morphology of the body wall}

As is well known Bonellia has a cigar-shaped trunk from the anterior end of which there extends dorsally to the mouth a very long and highly extensible proboscis which is homologous with the annelid prostomium. This consists of a long narrow stem and two terminal lobes. The animal whether inside or outside the burrow habitually lies on its dorsal surface and during feeding holds the proboscis with its dorsal aspect against the substrate.

The trunk body wall consists of an integument and three muscle layers (Plate I(a)). The integument is made up of an epidermis which is a simple columnar epithelium in which are found numerous mucous glands and a very deep connective tissue layer. The subepidermal connective tissue is equal in thickness to the circular and longitudinal muscle layers combined. The cuticle is represented by a fast-green positive layer about $1 \mu \mathrm{m}$ thick as shown by Masson's trichrome technique. The outermost muscle layer of the trunk consists of circular fibres, underlying which is a thicker layer of longitudinal muscle fibres. Internal to the longitudinal muscle is a layer of oblique muscle fibres, bundles of which form a fine criss-cross meshwork. The two outer layers (i.e. circular and longitudinal muscle) are much more developed than the oblique muscle. The circular muscle does not form a continuous sheet but is divided into contiguous but discrete bands which are continuous round the animal. Measurements on fixed material showed that in an animal of trunk length $\mathbf{3} \mathrm{cm}$ the width of each circular muscle band antero-posteriorly was of the order of $63 \mu \mathrm{m}$ in areas where the muscles were relaxed. Numerous thick spirit blue-positive fibres as shown by the method of Elder \& Owen (1967) run radially in the body wall across the circular muscle layer. These are presumably elastic fibres (Elder, 19733). The fibres become finer and form a network in the subepidermal connective tissue and terminate in the basement membrane, (Plate I(b)). Finer and less numerous fibres cross the longitudinal muscle layer. There is a network of fibres round the muscle bundles. Lining the coelomic cavity is a thin mesothelium.

There are no internal septa subdividing the coelomic cavity so that the muscles of the animal, which has no internal or external skeletal structures, operate against internal 

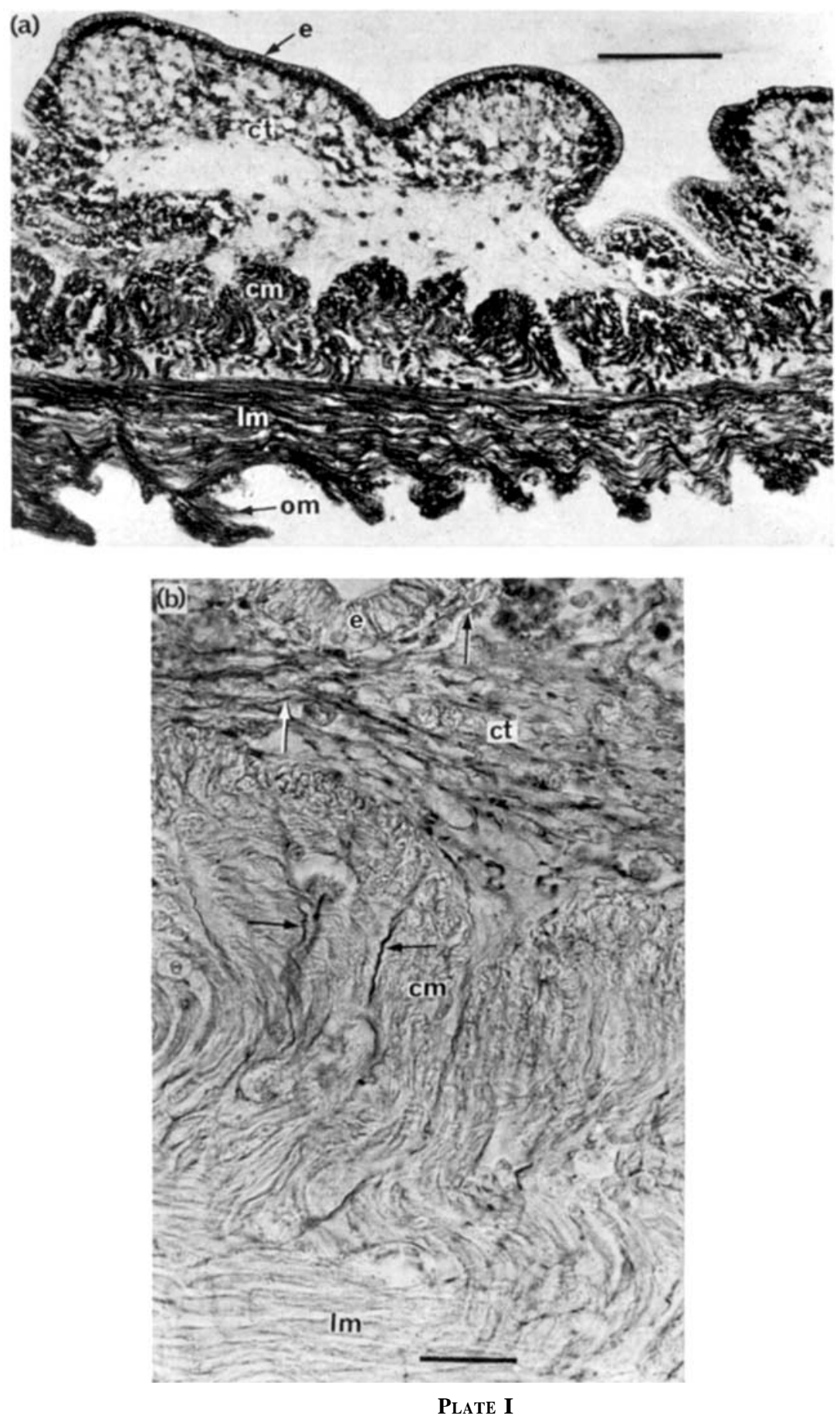
hydrostatic pressure and the trunk of the animal functions as one hydrodynamic unit. This is in contrast with many septate annelid worms in which each segment functions as a more or less separate unit.

\section{Peristalsis and burrow irrigation}

Peristaltic waves pass from the anterior end to the posterior end of the worm regularly. whether the worm is feeding or not. This peristalsis transports water anteroposteriorly and serves to irrigate the burrow which in nature is always open at both ends. When the animal is not passing a peristaltic wave the circular muscle layer is relaxed and the longitudinal muscles partly contracted, causing the worm to assume a cigar-like shape and jamming the body against the burrow walls (Fig. 1(a)). At the start of a peristaltic wave anteriorly the circular muscle in the anterior region contracts while the longitudinal muscle relaxes. This has two effects: the diameter of the anterior part of the animal is reduced while the posterior end bulges slightly backwards (Fig. 1(b), (c)). The animal must be anchored somewhere in the middle region by jamming against the burrow walls. As the wave of circular muscle contraction progresses posteriorly the circular muscle at the anterior end relaxes. The longitudinal muscle, at least at the anterior end, and possibly also the oblique muscle in this region maintain their tension and the trunk is "blown up" anteriorly again, jamming against the burrow walls and anchoring the trunk (Fig. 1(d), (e)). The wave of circular muscle contraction finally reaches the posterior tip of the trunk (Fig. (1(f)-(i)) and as this happens the posterior bulge produced as a result of the start of the wave of circular muscle contraction is withdrawn. In other words, there is no net locomotion as a result of this type of peristaltic irrigatory wave.

The rate of peristaltic wave production varies with the state of activity of the animal. Thus, when the animal is at rest, peristalsis takes place at an average rate of 4.8 waves per minute (at $26^{\circ} \mathrm{C}$ ), while during feeding, the average rate of peristalsis usually goes up to 5.7 waves per minute. This is presumably due to increased respiratory demand. Although the rate of wave initiation is different, the rate at which the irrigatory waves are propagated are the same in both feeding and resting states. This rate is of the order of $2.4 \mathrm{~mm} / \mathrm{sec}$ at a temperature of $26^{\circ} \mathrm{C}$. During irrigation an animal of about $3.5 \mathrm{~cm}$ in length (dry weight $1.8771 \mathrm{~g})$ pumps water through the burrow at the rate of $25-51 \mathrm{ml} / \mathrm{hr}\left(25^{\circ} \mathrm{C}\right)$.

As observed by Lawry (1966a) for Urechis, the velocity of the peristaltic waves decreases as the waves approach the anal region. Some water is sometimes expelled from the anus when the antero-posterior peristaltic wave enters the anal region. When this happens a faecal pellet is sometimes expelled from the anus. As opposed to the case in Echiurus (Gislén, 1940; Nyholm \& Borno, 1969) and Ochetostoma (Chuang, 1962), we could not observe periods of complete rest in Bonellia during which no peristalsis takes place. However, when the animal is not feeding, the peristaltic waves are occasionally extremely

Plate I. (a) Longitudinal section of the trunk body wall of $B$. viridis. Note the very deep and compressibleconnective tissue layer into which the epidermal folds are accommodated. Note also the three muscle layers. Masson stain. Scale $100 \mathrm{pm}$. (b) Longitudinal section of the trunk integument, the circular, and the longitudinal (in part) muscle layers. Spirit blue-positive fibres (arrows) form a network in the subepidermal connective tissue layer and run radially across the circular muscle layer. Spirit blue and picro-fuchsin stain. Scale $20 \mathrm{pm}$. cm, circular muscle; ct, subepidermalconnective tissue; e, epidermis;lm, longitudinalmuscle; om, oblique muscle. 
(a)

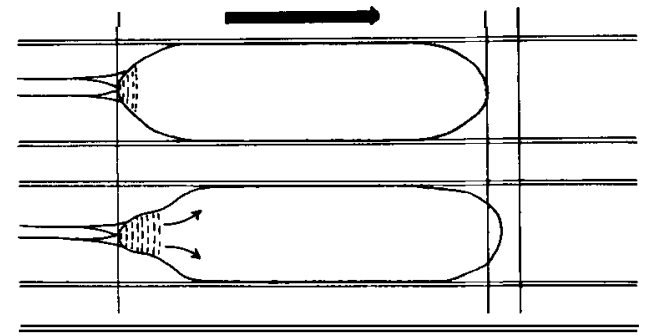

(c)

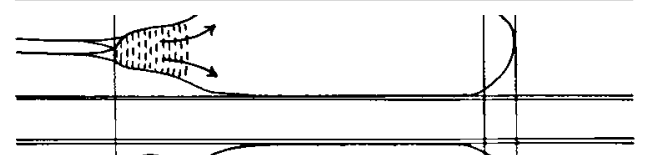

(d)

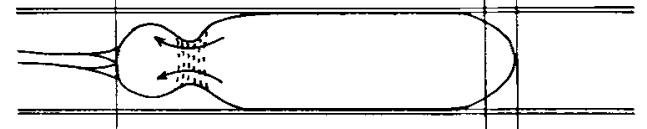

(e)
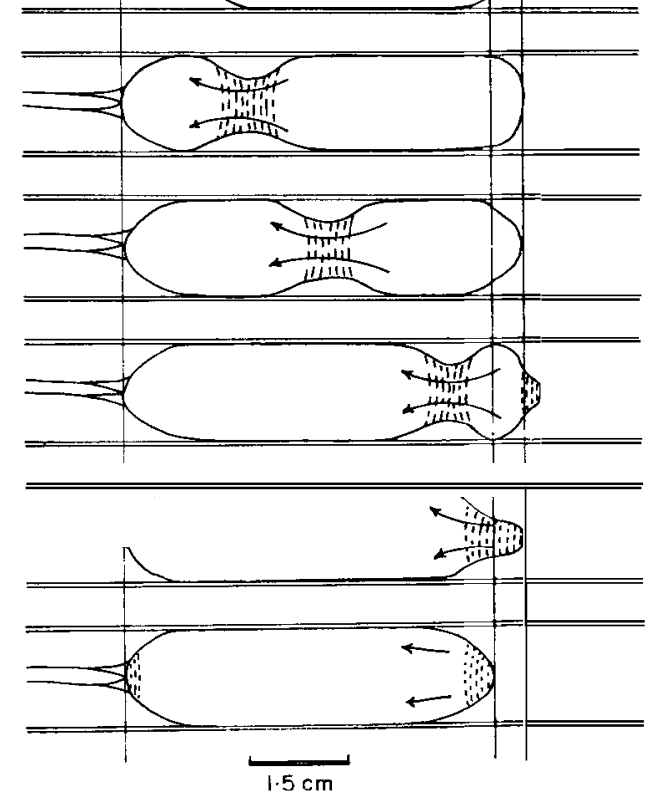

Fig. 1. Successive stages during the passage of a peristaltic irrigatory wave antero-posteriorly in $B$. viridis confined in a glass tube. The animal is with the ventral side upwards and is viewed from above.

Note: In all figures a broad solid arrow indicates the direction of the wave of circular muscle contraction and the broad open arrow indicates the direction of movement of the trunk. The thin arrows show the direction of movement of the coelomic fluid and viscera. The stippling indicates the regions of circular muscle contraction.

shallow and initiated at a very slow rate so that they are only observable with difficulty. Fisher \& MacGinitie (1928), Fisher (1946) and Hall (1931) working with Urechis all record periods of absolute rest, in which no perceptible movement of any sort takes place. Lawry (1966a), however, recorded continually the activity of Urechis over an eight-day period and found that only for one hour in the entire eight days did the worm "rest" and generally it was continuously active over each $\mathbf{2 4}$ hour period. 


\section{Locomotion in the burrow}

\section{Antikinetic locomotion}

In antikinetic forward locomotion of Bonellia, the longitudinal muscles in the anterior region relax while the circular muscles in this same region contract. Since the trunk is anchored posteriorly against the walls of the burrow due to the partial contraction of the longitudinal muscle and possibly also the oblique muscle in this region, with the antagonistic extension of the circular muscle, the anterior end is protruded (Fig. 2(b), (c)).

(a)

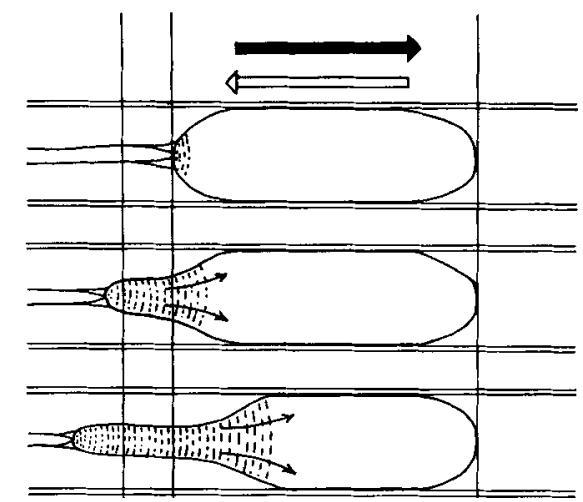

(d)

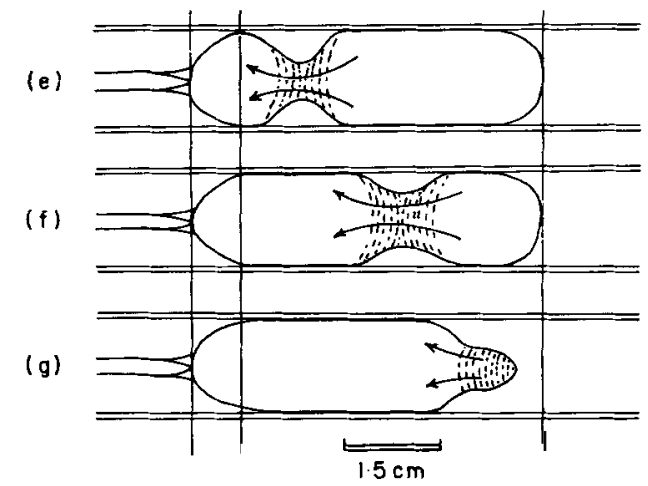

FIG. 2 (a)

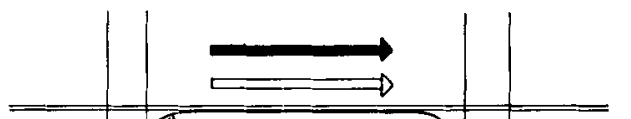

(b)

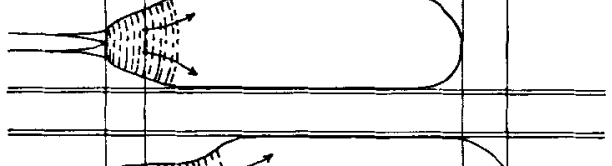

(c)

(d)

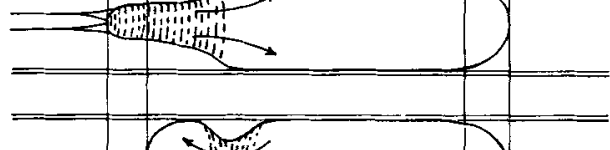

(e)

( $f$ )

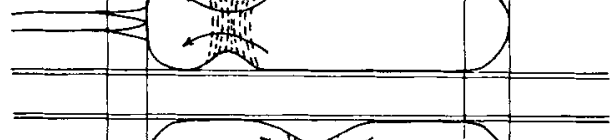

(g)

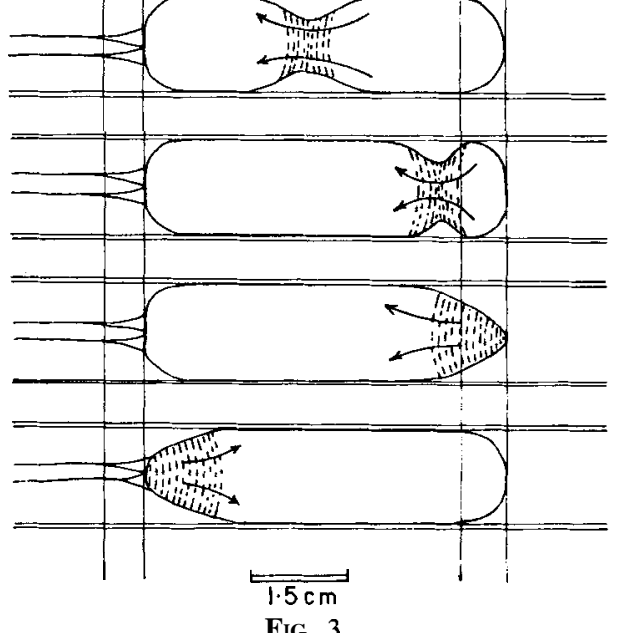

Fig. 2. Successive stages in antikinetic forward locomotion. Animal viewed from above. (See note in Fig. 1.)

Fig. 3. Successive stages in synkinetic backwards locomotion. Animal viewed from above. (See note in Fig. 1.)

As in the irrigation movements described in the previous section, as the wave of circular muscle contraction progresses posteriorly, the longitudinal muscle in the anterior region contracts, causing this region to expand and jam against the burrow walls, in this manner anchoring the body anteriorly (Fig. 2(d), (e)). As the wave of circular muscle contraction reaches the posterior region, there is also contraction of the longitudinal muscles and the 
posterior end of the body is pulled forward by the same length that the anterior end has previously protruded forwards (Fig. 2(f), (g)). In this way the animal moves forwards as a wave of contraction moves backwards. This is antikinetic progression.

As explained by Gray (1968) for this to happen the animal must be anchored at the point of maximum contraction of the longitudinal muscles. Close observation under the dissecting microscope of the passage of a wave of circular muscle contraction along the trunk has shown in fact that the papillae of the integument are most closely spaced in the regions of the trunk expanded against the wall of the glass tube and least closely spaced in the region of circular muscle contraction. This indicates that the longitudinal muscles are fully contracted in the transversely expanded regions, i.e. at the points d'appui. This is as predicted by theory.

An average speed of locomotion of $0.4 \mathrm{~mm} / \mathrm{sec}$ has been recorded for an animal moving forward in this manner in its glass tube. The wave of circular muscle contraction progresses posteriorly with a velocity of $4.27 \mathrm{~mm} / \mathrm{sec}$ relative to the substrate.

The essential difference between this type of movement in which peristalsis produces locomotion and the case when it produces irrigation with no net movement must lie in the relative degrees of relaxation and contraction of the longitudinal, circular and oblique muscles in the region of the body posterior to the wave of contraction. In irrigatory peristalsis the wave of contraction of circular muscles anteriorly produces slippage and extension of the trunk posteriorly (Fig. 1(a)-(c)) so that in fact no forward protrusion of the anterior end results and hence the animal re-establishes a point d'appui anteriorly at the same level as before the commencement of the wave. On the other hand, in locomotory peristalsis no slippage backwards of the posterior region occurs (Fig. 2(b), (c)) and the anterior end protrudes forwards and establishes a new point d'appui anterior to the previous one. This means that in irrigation in addition to the obvious wave of contraction passing backwards there must be partial contraction of the circular and possibly also the oblique muscles to allow slippage of the posterior region, while in locomotion there is no such partial contraction and the trunk is firmly anchored behind the region of the peristaltic wave. This difference between irrigatory and locomotory peristalsis suggests that the activities are not exclusively under central control but that reflex activity with input from peripheral sensory receptors is involved.

Backward antikinetic locomotion is also frequently observed in Bonellia with the peristaltic wave starting at the posterior end. Bonellia moves forwards and backwards antikinetically at comparable velocities.

\section{Synkinetic locomotion}

In addition to forward and backward antikinetic locomotion, synkinetic backward locomotion has also been observed. The circular muscles of the anterior region contract while the longitudinal muscles relax. In this way there is a narrowing of the diameter of the anterior region. As this happens the posterior end of the animal extends backwards presumably because of a very slight contraction of the circular and possibly also of the oblique muscles posteriorly which allows slippage of the posterior region (Fig. 3(a)-(c)). The animal must be anchored in the intermediate region. This is followed by contraction of the longitudinal muscle and relaxation of the circular muscle anterior to the peristaltic wave so that a new point d'appui is established at the anterior region but displaced backwards in relation to the original one (Fig. 3(c), (d)). The wave continues backwards and as 
it reaches the posterior end, this is pushed backwards (Fig. 3(e)-(g)). The peristaltic wave moves backwards as does the animal, hence locomotion is synkinetic.

Theory requires that for locomotion to be synkinetic, the longitudinal muscle must be relatively relaxed at the point d'uppui (Gray, 1968). Observation under the dissecting microscope of the spacing of the papillae on the trunk has shown that the papillae are least closely spaced in those regions of the trunk pressed against the glass tube and most closely spaced in the region of the circular muscle contraction. This indicates that the longitudinal

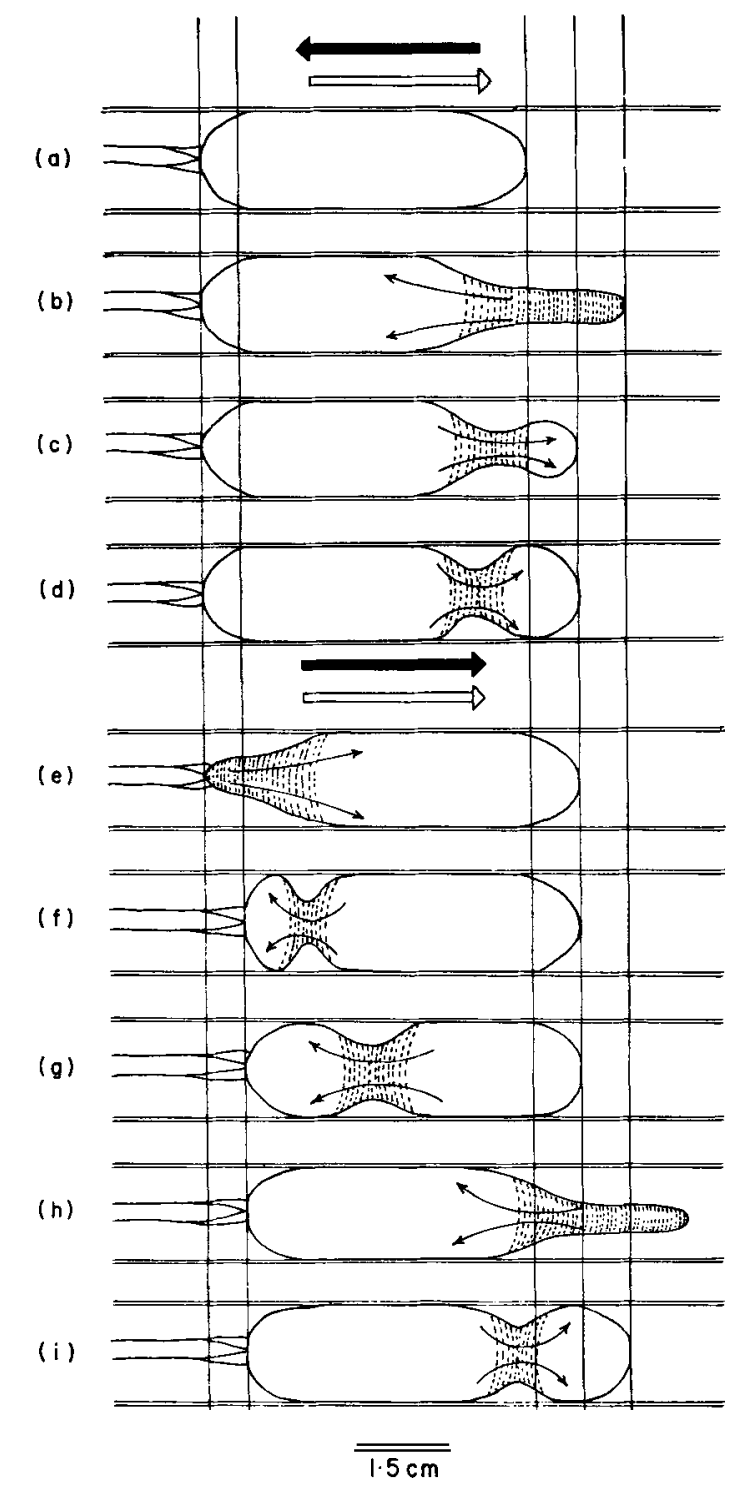

FIG. 4(a)-(i). Successive stages in backwards locomotion of $B$. viridis by antikinesis and synkinesis in strict alternation. Figs. (a)-(d) show antikineticstages and (e)-(i) synkinetic stages. Animal viewed from above. (See note in Fig. 1.) 
muscles are most relaxed at the expanded regions of the trunk (i.e. at the point d'appui). What is more interesting is that in the constricted region both circular and longitudinal muscles are contracted at the same time, and conversely, in the expanded regions in front and behind, both the longitudinal and circular muscles are relatively relaxed. The significance of this and some of the morphological adaptations involved will be treated in the discussion.

\section{Synkinetic and antikinetic locomotion in strict alternation}

In this type of locomotion, antikinesis alternates with synkinesis (Fig. 4(a)-(i)). The peristaltic locomotory wave starts at the posterior end and travels anteriorly producing backward movement (Fig. 4(a)-(e)) in the way described in the section on antikinetic locomotion. This is the antikinetic phase. The peristaltic wave now reverses direction, but the animal keeps moving in the original backward direction. This is the synkinetic phase (Fig. 4(f)-(i)) and produces locomotion in the way described in the section on synkinetic locomotion. The cycle is repeated resulting in a steady backward locomotion of the trunk. The antikinetic and synkinetic phases are approximately equal in duration each averaging about $5 \mathrm{sec}$.

\section{Passing through small holes}

An attempt was made to confine the worms to their observation glass tubes by stoppering the ends of the tubes with corks bored with $5 \mathrm{~mm}$ diameter holes to permit egress of the proboscis. However, it was soon evident that the worms could pass in and out of these narrow holes with ease. This is done in the following manner. The worm protrudes its proboscis out of the hole and moves its body up to the cork (Fig. 5(a)). The way the proboscis moves will be described in another paper. The circular muscles at the anterior end of the trunk contract fully when a peristaltic wave which has started at the posterior end of the animal reaches the anterior region and the anterior end is protruded out of the hole (Fig. 5(b)). As more peristaltic waves arrive anteriorly more of the anterior end is pushed out. The circular muscles in that part of the trunk which is protruding from the tube are then relaxed, while the longitudinal muscles are contracted, the anterior end thus expands and prevents the worm from slipping backwards (Fig. 5(c)-(g)). When approximately half of the trunk has passed out of the opening, postero-anterior peristalsis continues into the part of the trunk which is outside the tube (Fig. 5(h)-(k)). The whole process is continued till the whole animal has passed out of the hole. One should note that while the trunk progresses out of the hole by synkinesis the contracted region inside the hole is moving backwards relative to the animal. During the entire operation the worm is aided by contraction of the proboscis whose terminal lobes are attached to a substrate. A $7 \mathrm{~cm}$ long animal can pass out of a $5 \mathrm{~mm}$ diameter hole in $44 \mathrm{sec}$.

\section{Turning in the burrow}

The worms often turn round in their burrows. Before doing this the proboscis is retracted and coiled up in front of the trunk (Fig. 6(a)). The anterior end of the animal is twisted backwards by a unilateral contraction of the longitudinal muscles midventrally in the region immediately posterior to the front end. At the same time, the longitudinal muscle diametrically opposite the region of contraction is relaxed. This turning is helped 


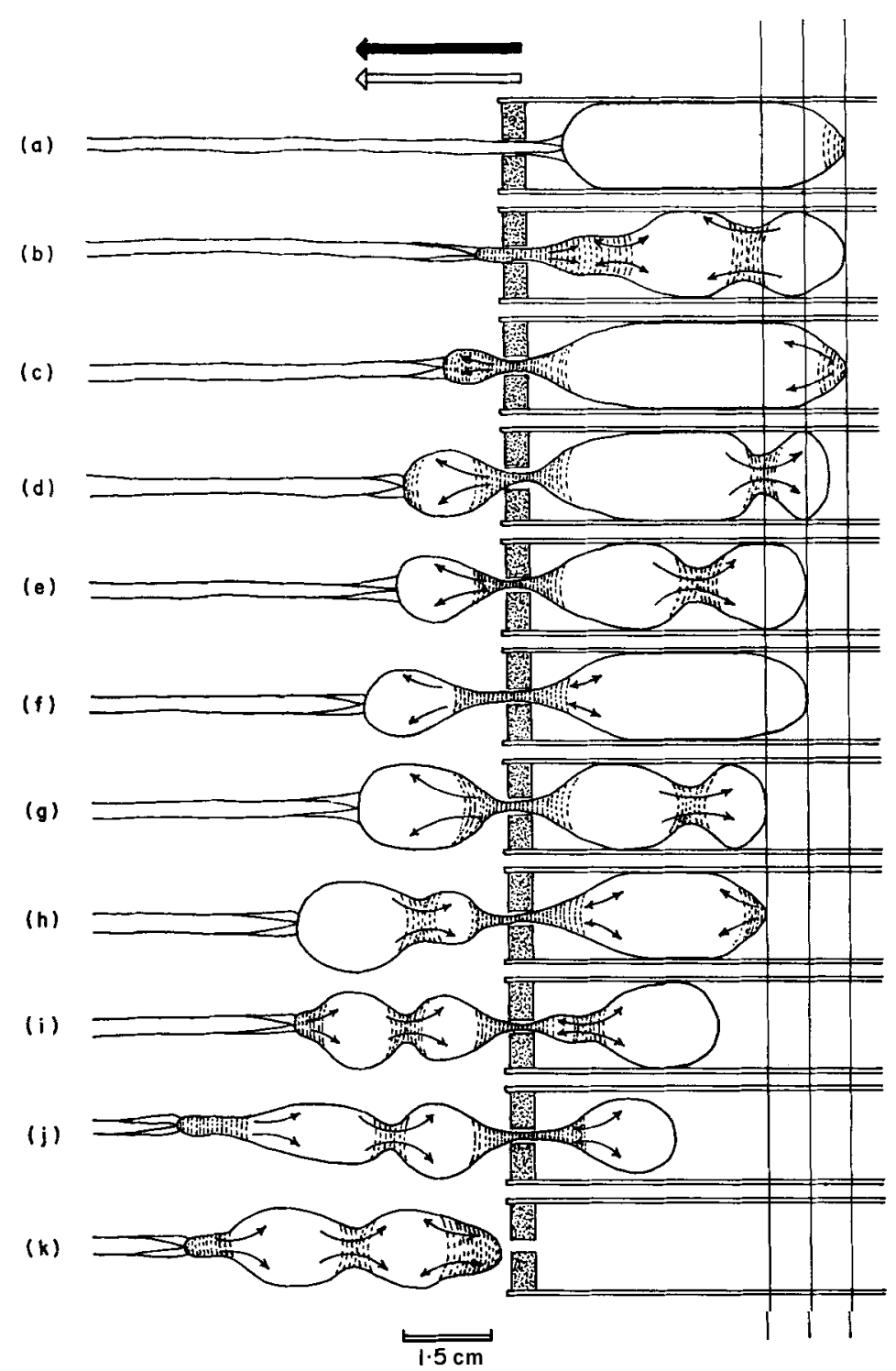

Fig. 5. Successivestages in the passage of the trunk through a narrow hole. Animal viewed from above. Note that the contracted region of the trunk inside the hole moves back relative to the animal. (See note in Fig. 1.)

by peristaltic waves of the body wall travelling backwards thus increasing the hydrostatic pressure transmitted to the anterior region (Fig. 6(b), (c)). Doubling up of the anterior end of the trunk proceeds as the region of midventral longitudinal muscle contraction (i.e. the inside of the bend) moves morphologically backwards. The doubling up necessitates a narrowing and a lengthening of the anterior region which is achieved by contraction of the circular muscle and relaxation of the longitudinal muscle except in the inside of the bend (Fig. 6(b), (c)). 

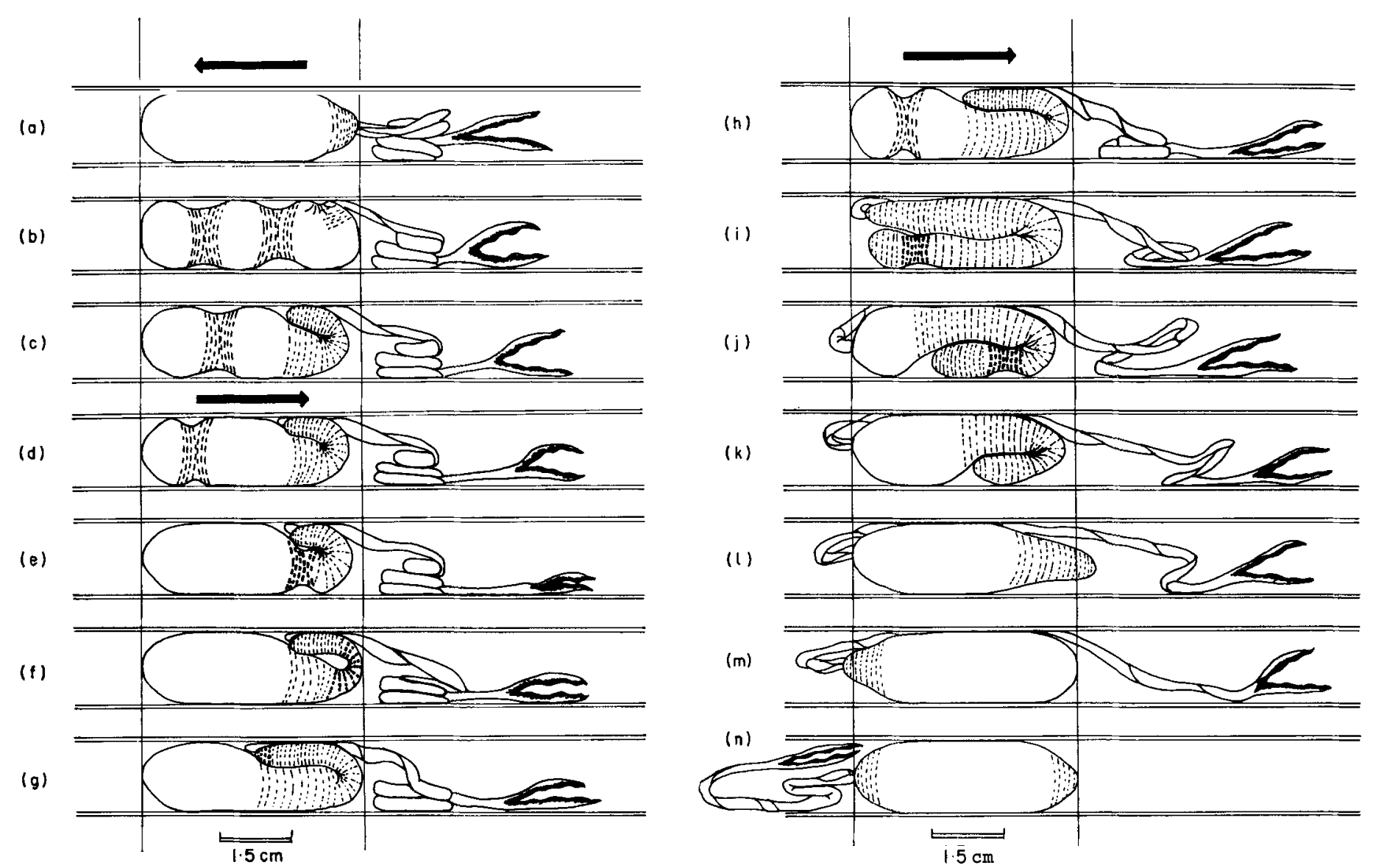

Fig. 6. Successive stages in the turning of $B$. viridis in its glass tube. Animal viewed from the side. The heavier stippling indicates the passage of a peristaltic wave along a region where the circular muscle is already partly contracted. (See note in Fig. 1.) 
Further doubling up is now effected by means of peristaltic waves which travel posteroanteriorly (Fig. 6(d)-(h)). As a wave reaches the region of doubling up the twisted anterior end protrudes further backwards by relaxation of the longitudinal muscle in the inside of the bend (Fig. 6(e)-(g)). This process is continued until the anterior tip of the trunk has been brought behind the posterior end (Fig. 6(h), (i)). The anterior end in now blown up to form apoint d'appui (Fig. 6(j)).

The process is now one of straightening the doubled up trunk by contraction of the longitudinal muscles in the region anterior to the point d'appui especially round the outside of the bend in the trunk. As is to be expected this part of the process is quite fast and appreciably faster than the previous stages (Fig. 6(k), (1)).

During turning of the trunk the main body of the proboscis has been left in its original position. Bringing the proboscis to lie completely in front of the turned trunk is a relatively simple matter. It is brought about in stepwise fashion by contractions of that part of the proboscis which is wedged between the trunk and the burrow wall and of that part which lies immediately anterior to this region (Fig. 6(m), (n)).

A $6 \mathrm{~cm}$ long animal can turn its trunk completely in the burrow in $\mathbf{4 4} \mathrm{sec}$, while it can bring its proboscis from behind the trunk to a position in front in a further $56 \mathrm{sec}$.

Movements and locomotion in the free animal

When the animal is removed from its burrow, it performs a variety of movements and is able to move over the substrate. When the animal is placed on a rough surface, such as a gravelly bottom, it is able to move quite fast. When placed on a smooth surface (e.g. a shiny perspex sheet) the animal is also able to move, though at a slower rate. Since the trunk in a freely moving animal has not the external constraints which are present when the animal is in a narrow burrow, consideration of its movements throws a special light on the relative involvement of the various muscle layers in locomotory and other movements.

Peristalsis in the free animal may take place in either direction. As a wave of circular muscle contraction passes back along the animal this manifests itself as a constriction which moves antero-posteriorly (Fig. 7(b)-(d)). Following this wave of circular muscle contraction, the longitudinal muscle contracts as is evident from the bulge which travels backwards in the wake of the wave of circular muscle contraction. Following the passage of the wave of longitudinal muscle contraction, the longitudinal muscle is partly relaxed, while the circular muscle is partly contracted (Fig. 7(e)). When the wave of circular muscle contraction reaches the posterior end of the worm, the circular muscle in this region remains contracted and the posterior end protrudes backwards (Fig. 7(f)) and may subsequently execute a wide variety of exploratory movements (Fig. 7(g), (h)). During the process described above (Fig. 7(a)-(h)) the animal does not move over the substrate, and this phase may be regarded as the "exploratory phase". The "locomotory phase" starts when the posterior region is bent to one side (Fig. 7(i)) due to a unilateralcontractionofthe longitudinal muscle in the region of the bend and relaxation of the longitudinal muscle on the other side of the trunk in the same region. The longitudinal muscle posterior to the bend is contracted to give rise to a characteristic "bulge" (Fig. 7(j)). The circular muscle contraction proceeds anteriorly as a constriction followed by the "bulge" (Fig. 7(k)). This causes the worm to move backwards (Fig. 7(1)). Thus during the "locomotory phase" the trunk can move antikinetically. The free animal can also progress by means of antikinetic and synkinetic waves in alternation as described in a previous section. 


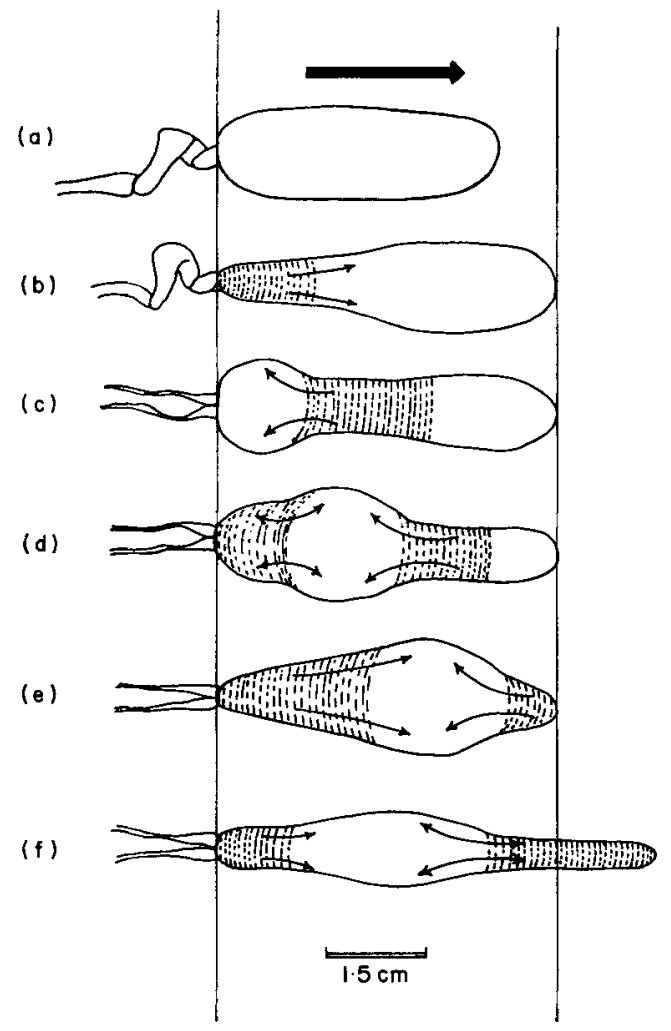

(g)

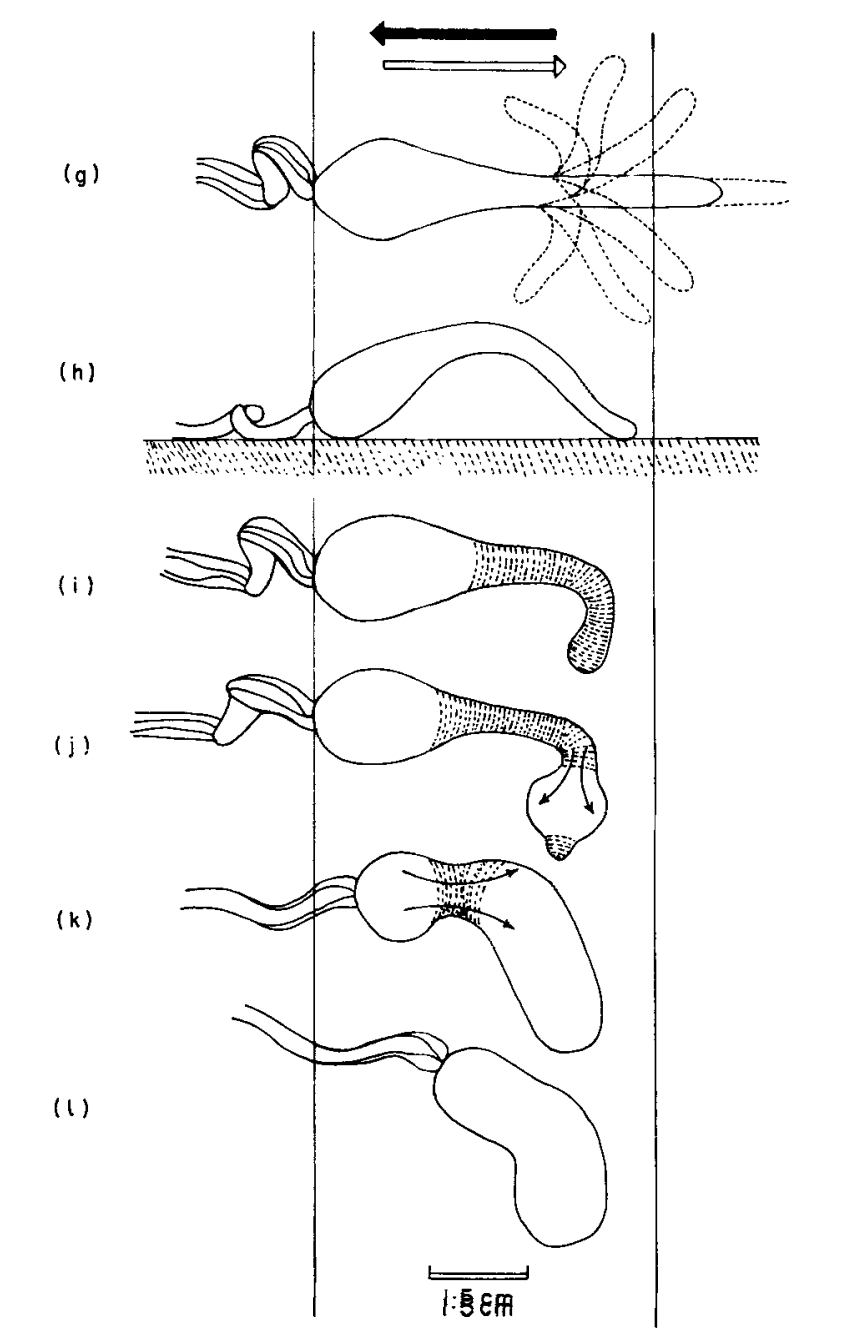

$(\mathrm{h})$

FIG. 7(a)-(1). Movement in a free $B$. viridis on a smooth substrate. (a)-(f) Peristalsis: the animal is viewed from above exercising without locomotion. (g), (h) Exploratory movements : (g) animal viewed from above, (h) animal viewed from the side. (i)-(1) Antikinetic backwards locomotion with the animal viewed from above. (See note in Fig. 1.)

In the free animal, anchorage can no longer be made against the burrow walls. In the "exploratory phase", the worm must be anchored anteriorly to enable the posterior end to elongate and "explore". This anterior anchor is provided by the frictional resistance of the trunk against the substrate which is much greater than that produced between the posterior region and the fluid medium, in which this end is most of the time waving during the "exploratory phase" (Fig. 7(a)-(h)). The attachment of the anterior end to the substrate is aided by the copious secretion of numerous mucus glands found in the integument of this animal. The weight of the proboscis lying in front of the anterior end must also help in anchoring it down. 
During the locomotory phase, the posterior end of the body must be anchored and the anterior anchor released if the worm is to move backwards (Fig. 7(i)-(1)). The posterior anchor is provided partly by the initial posterior bulge and partly by the bending of the posterior half of the trunk. The bulge touches the substrate and provides friction, again aided by the adhesiveness of the mucus. The animal may also hook on to any projection or irregularity provided by the substrate. The flexing of the posterior half of the body gives it a better purchase against the substrate and a lateral thrust is developed during a forward wave of unilateral longitudinal muscle contraction. A similar mechanism in which flexure of the body provides anchorage for locomotion has been described for Priapulus caudatus by Hammond (I970).

\section{Discussion}

Absence of septa

Whether the absence of septa in the Echiura is a primitive condition (Baltzer, 1931; Clark, 1969) or a secondary adaptation (Dawydoff, 1959) the possession of an unsegmented coelom is without any doubt of great adaptive value to burrow living animals (Mettam, 1969). One of the main problems of such a mode of life is irrigation of the burrow for respiratory purposes. A widespread mechanism is peristaltic pumping and for this to be efficient the animal must be able to produce a tight fit in the burrow. Since this mechanism requires radial expansion of consecutive segments of the body wall down the length of the animal it is clear that absence of septa would be advantageous and many worms (e.g. arenicolids and terebellids) which produce their own burrow are largely aseptate (Mettam, 1969). A fortiori in animals, like Bonellia, which live in ready-made burrows, and hence necessarily inhabit burrows with a range of diameters, absence of septa is very beneficial. In such animals, this absence in turn makes possible a variety of modes of peristaltic locomotion.

\section{Peristaltic locomotion}

As was pointed out by Trueman \& Ansell (1969) whereas all septate animals must use peristaltic waves which are antikinetic to move along a burrow, those with a continuous body cavity may utilize either synkinetic or antikinetic waves for this purpose. This follows from the fact that synkineticlocomotion requires maximum longitudinal extension at the point $d$ 'appui and the establishment of a point d'appui in a burrow itself requires radial expansion. It is clear that only aseptate animals can achieve both requirements in the same region, since this involves a volume change which is obviously impossible within fluid-tight segments, Our observations bear this out and show that the aseptate Bonellia employs both types of waves with equal ease and indeed sometimes employs the two types in strict alternation to produce a steady unidirectional locomotion.

Mettam (1969) proposed a simple scheme to illustrate four possible types of locomotory peristalsis in tubicolous worm-like animals. The animals may be able to move in their burrow or tube either by a wave of constriction or by a wave of dilatation passing along the body and in either case the wave may be either retrograde or direct. Applying his model to real animals Mettam states that his type (b) (i.e. locomotion by a direct wave of constriction) has never been observed in its extreme form although it may occur in combination with type (d) (i.e. locomotion by a direct wave of dilatation). This gap in the 
application of Mettam's theoretical scheme was first made good by the observations of Elder $(1973 a)$ on the aseptate annelid Polyphysia crassa. Bonellia provides a second example. A similar mechanism was recorded by Hunter \& Elder (1967) for the holothurian Leptosynapta tenuis. Further examples of progression by direct peristaltic waves of constriction will probably be found as more aseptate burrow-inhabiting vermiform animals are studied.

One asks what is the functional significance of the versatility of locomotory patterns found in Bonellia. The answer we believe lies in the fact that Bonellia does not dig its own burrow but takes over ready-made burrows and therefore has to be able within limits to accommodate its transverse dimensions to those of the burrows available to it. On theoretical considerations it appeared to us that synkinetic locomotion would be the preferred mode in narrow burrows and antikinetic locomotion in wide burrows. The trunk of Bonellia in locomotion operates at constant volume, at least over relatively long periods since at no time during peristalsis of the trunk was any enlargement of the base of the proboscis nor any inhalation and exhalation of water through the mouth or anus observed. Since during synkinetic locomotion the animal anteriorly and posteriorly to the peristaltic constriction must have both its longitudinal and circular muscles extended, it is clear that in burrows above a given diameter the animal cannot easily achieve all round effective contact with the walls of the burrow at the points d'appui, and the animal has to switch to the antikinetic mode or to a combination of synkinesis and antikinesis. In the antikinetic mode the longitudinal and circular muscles at each particular antero-posterior level act antagonistically and as the burrow increases in diameter the animal easily compensates by increasing the extent of contraction of the longitudinal muscle anteriorly and posteriorly to the peristaltic constriction. Above a certain diameter the animal would behave as it does when lying outside a burrow.

These theoretical considerations were fully supported by an experimentin which the same animals were observed in tubes of progressively smaller diameters. In the widest tubes the animals behave essentially as free animals. In the next narrower tubes the same animals at times move antikinetically and at other times synkinetically. In still narrower tubes locomotion is in three different ways at different times: (a) antikinetic (b) synkinetic and (c) synkinetic antikinetic in strict alternation. In still narrower tubes the animals move exclusively synkinetically. Below a certain diameter of tube the animals are immobilized. Thus it is clear that the ability to adopt the antikinetic or the synkinetic mode or a combination of both enables the animal to negotiate easily burrows within a range of diameters. This and the ability to turn inside the burrow and to pass through small holes are manifestly of great importance to an animal like Bonellia.

\section{The integument and elastic fibres}

Mathematical computations of the enveloping surface area of the whole trunk at different phases of both the antikinetic and synkinetic cycles of locomotion show that there are no significant changes in the total enveloping area. However, it is clear that both synkinetic and antikinetic peristalsis involve considerable changes in the enveloping surface area of particular segments of the trunk. Since the cuticle must be relatively inelastic these changes necessitate considerable crumpling and uncrumpling of the epidermis. Moreover in synkinetic peristalsis there is a very considerable increase in the thickness of the body wall during the passage of a wave of constriction 
since this is brought about by simultaneous contraction of both the longitudinal and the circular muscle. The integument and body wall show several adaptive features for these conformational and dimensional changes. The extreme thinness of the cuticle (about $1 \mu \mathrm{m}$ ) allows great flexibility and the epidermis is thrown "nto both longitudinal and transverse corrugations. The subepidermal connective tissue layer is very deep and can accommodate considerable crumpling of the epidermis. The radial spirit blue-positive fibres crossing the circular muscle layer and the subepidermal network of the same type of fibres presumably control the folding of the epidermis. In all these features Bonellia shows remarkable convergence with the polychaete Polyphysia crassa which progresses by means of synkinetic peristaltic waves of constriction (Elder, 1973a).

This work involved the use of equipment obtained by a grant from the Development Fund of Barclays Bank International towards the setting up of the Fort San Lucian Marine Station.

The authors thank Professor G. M. Hughes for helpful criticismin the preparation of this paper. They also wish to thank Professor J. L. Pace for the use of photographic facilities and Dr A. Cuschieri, Mr C. Borg Galea and Mr A. Micallef for help with the photography. Thanks are due to $\operatorname{Dr} S$. Fiorini for help with the mathematical computations.

\section{REFERENCES}

Baltzer, F. (1931). Echiurida. In Handbuch der Zoologie 2 (9): 62-168. Kiikenthal, W. \& Krumbach, T. (Eds). Berlin and Leipzig: De Gruyter.

Chuang, S. N. (1962). Feeding mechanisms of the echiuroid, Ochetostoma erythrogrammon Leuckart and Rueppell, 1828. Biol. Bull. mar. biol. Lab., Woods Hole 123: 80-85.

Clark, R. B. (1964). Dynamics in metazoan evolution. Oxford: Clarendon Press.

Clark, R. B. (1969). Systematics and phylogeny: Annelida, Echiura, Sipuncula. In Chemical zoology 4: 1-68. Florkin, M. \& Scheer,B. T. (eds). New York and London: Academic Press.

Clark, R. B. \& Clark, M. E. (1960). The ligamentary system and the segmental musculature of Nephtys. Q. Jl microsc. Sci.101: 149-176.

Dawydoff, C. (1959). Classe des Echiuriens. In Traité de Zoologie 5 (1): 855-907. Grassé, P.-P. (ed.) Paris: Masson.

Elder, H. Y.(1973a). Direct peristaltic progression and the functional significance of the dermal connective tissues during burrowing in the polychaetePolyphysia crassa (Oersted).J. exp. Biol. 58: 637-655.

Elder, H. Y . (19736). Distribution and functions of elastic fibres in the invertebrates. Biol. Bull. mar. biol. Lab., Woods Hole 144: 43-63.

Elder, H. Y.\& Owen, G. (1967). Occurrence of “elastic”' fibres in the invertebrates. J. Zool.,Lond. 152: 1-8.

Fisher, W. K. (1946). Echiuroid worms of the North Pacific Ocean.Proc. U.S. natn. Mus. 96: 215-292.

Fisher, W. K. \& MacGinitie, G. E. (1928). The natural history of an echiuroid worm. Ann. Mag. nat. Hist. (10) 1: 204-213.

Forbes, E. \& Goodsir, J. (1841). On the natural history and anatomy of Thalassema and Echiurus. Edinb. New Phil.J. 30:369-378.

Gislén, T. (1940). Investigations on theecology of Echiurus.Lunds Univ. Arsskr. N. F.36 (10): 1-35.

Gray, J. (1939). Studies in animal locomotion. VIII. The kinetics of locomotion of Nereis diversicolor. J. exp. Biol. 16: 9-17.

Gray, J. (1968). Animallocomotion. London: Weidenfeld and Nicolson.

Gray, J. \& Lissman, H. W. (1938). Studies in animal locomotion. VII. Locomotion reflexes in the earthworm. J.exp. Biol. 15: 506-517.

Hall, V. E. (1931). The muscular activity and oxygen consumption of Urechis caupo. Biol. Bull. mar. biol. Lab., Woods Hole 61: 400-416.

Hammond, R. A. (1970). The burrowing of Priapulus caudatus. J.Zool., Lond. 162: 469-480.

Hunter, R. D. \& Elder, H. Y. (1967). Analysis of burrowing mechanism in Leptosynapta tenuis and Golfingia gouldi. Biol. Bull. mar. biol. Lab., Woods Hole 133: 470.

Lacaze-Duthiers, H. de (1858). Recherches sur la Bonellie (Bonellia viridis). Annls Sci. nat. (Zool.) (4) 10: 49-110. 
Jaccarini, V. \& Schembri, P. J. (1977). Locomotory and other movements of the proboscis of Bonellia viridis (Echiura, Bonelliidae).J.Zool., Lond. 182: 467-476.

Lawry, J. V. (1966a). Neuromuscular mechanisms of burrow irrigation in the echiuroid worm Urechis caupo Fisher and MacGinitie. I. Anatomy of the neuromuscular system and activity of intact animals.J.exp. Biol. 45:343-356.

Lawry, J. V. (19666). Neuromuscular mechanisms of burrow irrigation in the echiuroid worm Urechis caupo Fisher and MacGinitie. II. Neuromuscular activity of dissected preparations. J. exp. Biol. 45: 357-368.

Mettam, C. (1969). Peristaltic waves of tubicolous worms and the problem of irrigation in Sabella pavonina. J. Zool., Lond. 158: 341-356.

Nyholm, K. -G. \& Borno, C. (1969). The oxygen intake of Echiurus echiurus Pallas. Zool. Bidr. Upps. 38: 255-261.

Rietsch, M. (1886). Etude sur les Géphyriens Armés ou Echiurens. Recl zool. suisse 3: 313-515.

Seymour, M. K. (1970). Skeletons of Lumbricus terrestris L. and Arenicola marina (L.). Nature, Lond. $228: 383$.

Seymour, M. K. (1971). Burrowing behaviour in the European lugworm Arenicola marina (Polychaeta: Arenicolidae). J.Zool.,Lond. 164:93-132.

Trueman, E. R. (1966a). Observations on the burrowing of Arenicola marina (L.). J. exp. Biol. 44: 93-1 18.

Trueman, E. R. (19666). The mechanism of burrowing in the polychaete worm Arenicola marina (L.). Biol. Bull. mar. biol. Lab., Woods Hole 131: 369-377.

Trueman, E. R. (1974). Locomotion of soft-bodiedanimals. London: Edward Arnold.

Trueman, E. R. \& Ansell, A. D. (1969). The mechanisms of burrowing into soft substrata by marine animals. Oceanogr. Mar. Biol. Ann. Rev. $7: 315-366$.

Wells, G.P. (1944). Mechanism of burrowing in Arenicola marina L. Nature, Lond. 154: 396.

Wells, G. P. (1949a). Respiratory movements of Arenicola marina L.: Intermittent irrigation of the tube, and intermittent aerial respiration. J. mar. biol. Ass. U.K. 28: 447-464.

Wells, G. P. (19496). The behaviour of Arenicola marina L. in sand, and the role of spontaneous activity cycles. J. mar. biol. Ass. U.K. 28: 465-478.

Wells, G. P. (1954). The mechanism of proboscis movement in Arenicola. Q.Jl microsc. Sci.95:251-270.

Wilson, B. C. (1900). Our north American Echiuroids. Biol. Bull. mar. biol.Lab., Woods Hole 1: 162-178. 